\title{
On the New Plan of Admitting Students at Columbia University
}

\section{Edward L. Thorndike}

To cite this article: Edward L. Thorndike (1921) On the New Plan of Admitting Students at Columbia University, The Journal of Educational Research, 4:2, 95-101, DOI: 10.1080/00220671.1921.10879184

To link to this article: http://dx.doi.org/10.1080/00220671.1921.10879184

册 Published online: 15 Dec 2014.

Submit your article to this journal $\pi$

Q View related articles $\sqsubset$

4 Citing articles: 1 View citing articles 진 


\title{
ON THE NEW PLAN OF ADMITTING STUDENTS AT COLUMBIA UNIVERSITY ${ }^{1}$
}

\author{
Transmitted by \\ Edward L. Thorndike \\ Teachers College, Columbia University \\ The First Quotation: Dean Hawkes
}

Fortunately it is possible to determine with scientific accuracy whether or not the mental test is a useful addition to our academic machinery. If it turns out, during a series of years, that the correlation between the marks received on the mental tests and the collegiate work of the students is distinctly higher than the correlation between the results of other types of entrance examinations and the college work, it would seem to be clear that the new plan of admission affords the best index that we have of the ability of a boy to carry college work. The correlation between the work of the entire freshman year for the students who entered by the new plan and their marks on the mental test is +0.65 . The most reliable data available indicate that the highest correlation that can be expected between the work of the freshman year and the results of the usual college entrance examinations is about +0.45 . This latter figure has been obtained not only from a statistical study of our own freshmen but from similar studies in another institution. Although it is too early to make a final statement regarding the matter, every indication points to the mental test as a most useful addition to our machinery of admission. It must be kept in mind that the group of students who are admitted to college under the new plan are very carefully winnowed before they are authorized to take the mental test. The correlations obtained should, therefore, be interpreted as referring to the new plan of admission as a whole rather than to the mental test alone.

${ }^{1}$ At the public meeting of the National Association of Directors of Educational Research at Atlantic City, March 30, 1921, Professor Thorndike discussed the new plan of admitting students to Columbia University. He based his discussion in part on these two quotations. The first is by Doctor Herbert E. Hawkes, Dean of Columbia College, and the second is by Doctor Adam L. Jones, Director of University Admissions. 
In addition to the use of the results of the mental test in admission to college, they have been most helpful in my office as an aid in arriving at a diagnosis of academic maladies. A boy who has a poor academic record and a low mental-test grade generally needs very different treatment from the student whose record is poor but whose mental-test mark is high. And in several cases the mental test has afforded the clue which has enabled my office in cooperation with the university physician so to advise the boy that he has not only escaped being dropped, but has become an excellent academic citizen.

The wise use of a new instrument like the mental test requires constant caution and scrupulous checking, but its apparent possibilities for usefulness are so fundamental and far reaching that a careful and scientific study of its significance is one of the important tasks of the next few years.

\section{The Second Quotation: Director Jones}

It will be remembered that the new method permits students whose school and character records are satisfactory to us to substitute this examination for the entrance examinations. Candidates still have the option of entering by the old method, and they still have the privilege of substituting for the entrance examinations certain of the examinations given in schools by the New York State Department of Education. The records of those electing the older method of admission were scrutinized with the greatest care. The requirements were very strictly enforced. Those entering by the New York State examinations were required to have 70 percent or higher in each subject and admission with conditions was allowed only in the case of those whose outstanding excellence more than made good a technical deficiency.

This requirement was most strictly enforced in the case of those who came from the best high schools where the instruction was of the highest quality, and where in consequence there was least excuse for a doubtful record. A student with a poor record from a good school is usually a bad risk. Students coming from small or poorly equipped high schools were treated with greater leniency. A good student may fail to make a first-rate record 
in a poor school. Where there was room for doubt, the candidate was required to take the mental test.

By far the most significant group so far as our system of admission is concerned was the group entering by the new method.

It was expected that this method would appeal strongly to enterprising and alert young men in places in which the New York State examinations are not given and where college entrance examinations are less well or favorably known than in schools from which our student body has usually been chiefly drawn. The expectation was more than realized, the number of candidates for the freshman class from a distance was much greater than in the past, and those who applied under these conditions were generally successful in the test. It should be remembered that only those whose school records and character records were entirely satisfactory were allowed to enter by the new method. They constituted, therefore, a picked group.

That they were a picked group is evident not only from the records which they presented for admission, but also from the records which they made in college. They have done remarkably well. There were, of course, borderline cases and a number of these have not turned out well, but in the group as a whole the failures were very few. Most of those who failed were students whose scores in the psychological examination were relatively low, but whose cases seemed to possess sufficient merit to warrant their being given a trial. Even in this group, most justified their admission to college. There were a very few with relatively high scores whose records in college were not wholly satisfactory. Careful examination showed that their failure to make first-rate records was due not to lack of intelligence nor to faulty preparation, but to failure to divide their time and energies properly among the many demands which come to the college student.

Meetings of instructors of freshmen regularly follow the making up of the mid-term and term records for the purpose of considering the cases of students whose records are unsatisfactory. In the meeting last November only two of the students among more than sixty whose records were unsatisfactory had made high scores in the psychological examination. The testimony of their instructors was unanimously to the effect that both students were fully able to do good college work. It appeared, however, 
that one of them had been devoting too great an amount of attention to athletics and other extra-curricular activities, while the other had been taking undue advantage of his first opportunity to become acquainted with a great city.

Later study has shown that with remarkably few exceptions the higher a student's score in the psychological examination, the better his record in college.

Several studies have been made in the course of the year bearing upon this point. Some of these have been made by Mr. Harold K. Chadwick of this office. Others have been prepared by Mr. Ben D. Wood of the Department of Psychology. In one of Mr. Chadwick's studies he considered one hundred and eighty men made up of groups of ten, each group having psychological examination grades lying within two degrees in the scale from 70 to 106. The grades of the highest ten covered a range of three degrees since there were fewer than ten within two degrees. With this exception each two degrees in the scale from 70 to 106 was represented by a group of ten, the first ten alphabetically being taken in each case. The total amount of work in points done by each group was plotted by grades. The result for three typical low, middle, and high groups is given below:

\begin{tabular}{c|r|r|r|r|r|r|r|r|r|r|r|r}
\hline \hline $\begin{array}{c}\text { Group } \\
\text { Scores } \\
\text { Between }\end{array}$ & \multicolumn{10}{|c|}{ Amount of Work in Points at Each Given Grade } \\
\cline { 2 - 3 } & F & D - & D & D + & C - & C & C + & B & B & B & A & A \\
\hline 70 and 72 & 33 & 0 & 13 & 2 & 12 & 26 & 8 & 6 & 21 & 4 & 0 & 0 \\
86 and 88 & 9 & 3 & 14 & 4 & 10 & 18 & 25 & 8 & 36 & 7 & 3 & 3 \\
104 and 106 & 0 & 0 & 9 & 0 & 7 & 24 & 18 & 19 & 54 & 16 & 3 & 16 \\
\hline
\end{tabular}

The progressive decrease of low grades and increase of high grades as we go from the low to the high groups is significant. It was found to hold good very generally throughout the eighteen groups though there were a few exceptions.

No group of men with psychological examination grades below 78 received A's, only one group below 84 received A's. No group above 100 received F's, only one above 95 did so.

In another study the work of groups covering five degrees was compared and the dividing mark, between the upper and upper middle quartiles, the lower middle and upper middle quartiles and the lower middle and lower quartiles were studied with the following results: 


\begin{tabular}{c|c|c|c}
\hline Group & $\begin{array}{c}\text { Dividing Line for } \\
\text { Lowest Quartile }\end{array}$ & $\begin{array}{c}\text { Dividing Line } \\
\text { Between Two Mid- } \\
\text { dle Quartiles }\end{array}$ & $\begin{array}{c}\text { Dividing Line for } \\
\text { Highest Quartiles }\end{array}$ \\
\hline $70-75$ & F & C- & C+ \\
$75-80$ & D & C- & C+ \\
$80-85$ & D + & C & B \\
$85-90$ & C- & C & B- \\
$90-95$ & C & B- & B \\
$95-100$ & C & B- & B \\
$100-105$ & C & C + & B+ \\
$105-$ & C + & B & \\
\hline
\end{tabular}

The men with higher grades did a larger amount of high-grade work and a smaller amount of low-grade work though the groups from 90 to 105 were practically the same so far as this study shows. It will be seen for example, that for the men with a psychological examination grade of 105 "C" marked the division between the lowest fourth and the remaining work while for those with a grade below 80 " $C$ " marked the division between the highest quarter and the remaining work; three-fourths of the work of the first was as high as the highest fourth of the work of the second group.

Another study of the work of students in the second session gave a number of striking results, all of which went to prove the progressive superiority of the higher groups in the order of their grades. The following is typical:

GROUP OF FIFTY FOR EACH TEN DEGREES OF THE SCALE

\begin{tabular}{|c|c|c|c|}
\hline \multirow{2}{*}{ Grades } & \multicolumn{2}{|c|}{ Number Dorng "B" Work or Better } & \multirow{2}{*}{$\begin{array}{c}\text { Percent of Ali. "B" } \\
\text { Men }\end{array}$} \\
\hline & $\begin{array}{c}\text { Individuals Out of } \\
\text { Group of Fifty }\end{array}$ & Percent of Group & \\
\hline $60-70$ & 2 & 4 & $33 / 4$ \\
\hline $70-80$ & 4 & 8 & $71 / 2$ \\
\hline $80-90$ & 7 & 14 & $131 / 4$ \\
\hline $90-100$ & 15 & 30 & $281 / 4$ \\
\hline $100-120$ & 25 & 50 & $471 / 4$ \\
\hline
\end{tabular}

1 "B men" were 21.2 percent of the 250 men. 
It should not be supposed, however, that the psychological examination alone would give ideal results particularly when the scores fall below 80 . The range from 60 to 70 was regarded as extremely doubtful. While the complete school records of all candidates were carefully examined, especially close attention was given to those whose scores were between 60 and 70, and only the most promising were admitted. The records show that this group did work practically equal to that for which the range was 70 to 80 and whose records had not been quite so carefully weighed.

The psychological examination alone would not be a fully satisfactory means of selecting students, but there has been no thought of using it without the student's complete previous record. Ordinarily the candidate's school record must show the completion of a school course covering the requisite entrance subjects with grades 10 percent or more above the school's passing mark. His personal record must show acceptable mental and moral qualities. Occasionally a student of especial promise with a record which is doubtful in certain particulars may be allowed to take the examination with the requirement that he pass with a very high grade.

It will be recalled that students who elect to enter by the old method take the psychological examination for purposes of record. This makes it possible each year to test the results of the psychological examination for practically every student in college.

A preliminary comparison of the relation between college record on the one hand and school record, entrance examination, regents' examinations, and psychological examination on the other was made at the close of the winter session by Mr. Ben D. Wood of the Department of Psychology. The results are significant. Among the students admitted by the college entrance examinations a good many doubtful cases were included. The correlation between their examinations and their college records was +0.43 which is reasonably satisfactory. The correlation between school record and college record was +0.45 . Those entering by regents' examinations were very carefully selected. The correlation between their examination and their college records was +0.57 , while the correlation between psychological examination and college record was +0.59 , a highly satisfactory result. This was for the first half-year only. 
A similar study for the work of the whole year shows a correlation between mental test and college record of +0.60 which was remarkably good. The correlation for the other examinations and for the school record has not yet been worked out. It should be remembered that there are many factors other than intelligence which determine a student's standing and that the psychological examination is not supposed to measure them.

The operation of the new system will be watched with the greatest care and no opportunity for checking its results or improving the methods of using it will be lost. It may still be an experiment, but it is certainly not a doubtful one. 